\title{
An Overview of Empty Container Repositioning Studies and Research Opportunities
}

\author{
Hüseyin Gençer \\ Piri Reis University, Turkey \\ E-mail: e.huseyin.gencer@googlemail.com \\ M. Hulusi Demir \\ Yaşar University, Turkey
}

Received: Dec. 19, 2018 Accepted: Jan. 10, 2019 Published: April 16, 2019

doi:10.5296/bmh.v7i1.14670 URL: http://dx.doi.org/10.5296/bmh.v7i1.14670

\begin{abstract}
The imbalances in world trade also affect container traffic and lead to large differences in import and export rates of many locations. As a consequence of this, the surplus containers are repositioned to locations where they are required, which causes high costs. Many studies in the literature have addressed this issue from different aspects. This study examines the studies and trends in empty container repositioning (ECR) practices and reveals the missing research areas in the literature. It discusses the mathematical models developed in the literature and addresses real-life applications of the liner carriers. The study also emphasizes how the opportunities in technological development can be used in ECR practices and provides suggestions for research topics that can be studied in the light of current trends in container shipping. It exhibits the actors involved in ECR operations and discusses the strategies applied in liner shipping. The main purpose of the study is to put forward research and real-life application opportunities in the field of ECR.
\end{abstract}

Keywords: empty container repositioning, container shipping, container logistics 


\section{Ml Macrothink}

\section{Introduction}

The container, which "made the world smaller and the world economy bigger", has been one of the most important catalysts of globalization. Since the container ensures safe, comfortable and intermodal transportation opportunities, it has made a revolution in transportation and has become one of the most preferred transportation types in international trade. The imbalances in the worldwide trade affect the container traffic directly and cause imbalances in the number of containers in many locations. In other words, export dominant locations have deficits in terms of number of containers and import dominant locations do surpluses. Consequently, surplus containers should be repositioned as empty to the locations where they are required.

Figure 1 shows the estimated cargo traffic on the main shipping routes in 2015. As can be seen, there are a lot of exports of containerized cargo from Asia to Europe. On the other hand, the imports to Asia from Europe are not even half of this rate. So it can be said that one of the two $20 \mathrm{dv}$ full containers going from Asia to Europe, will not be used after the containers have been unstuffed. On the other hand, containers are required in Asia to meet the demand for exports. Hence, the empty containers, which are not used in Europe, are transported back to the locations in Asia or to other locations where they are required.

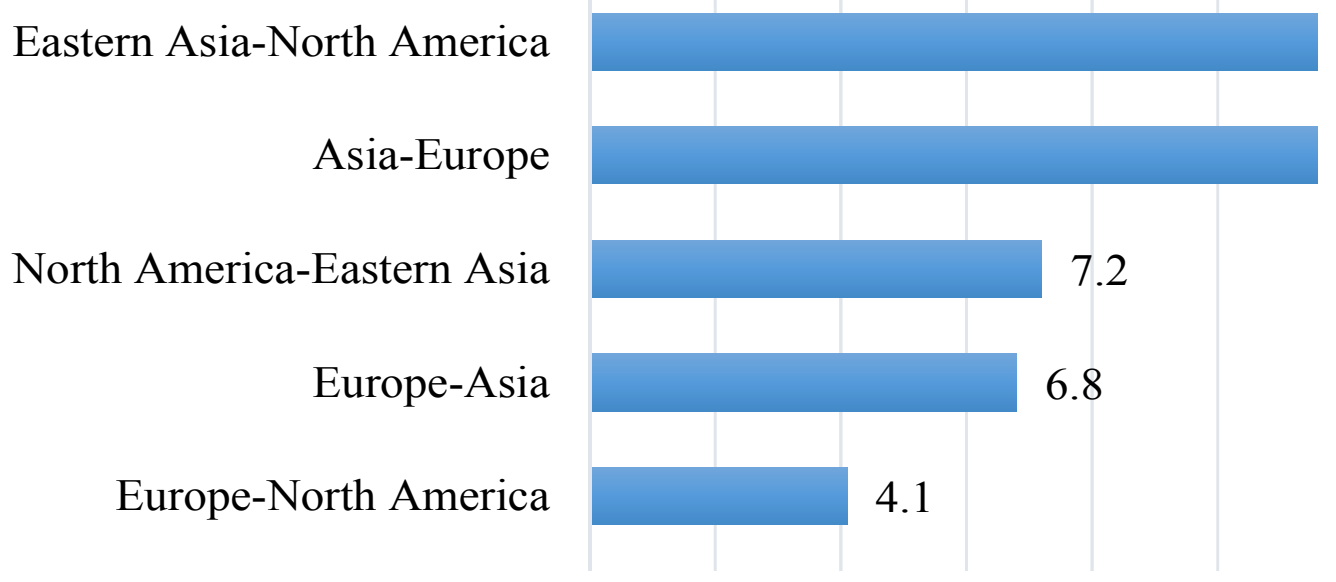

Figure 1. Containerized cargo flows on major trade routes in 2015 (in million TEUs) (Source: UNCTAD, 2016a, Lloyd's List, Statista)

As Figure 1 shows, another imbalance situation exists in the containerized trade between Europe and North America, and Eastern Asia and North America. A similar trade imbalance on the main routes is still present today. Empty containers that are held and handled at terminals and depots, and repositioned due to trade imbalances cause extra costs for the container shipping companies. In other words, while the shipping companies make money by carrying full containers, they spend money for the repositioning of empty containers. 
According to many experts, the total repositioning costs of empty containers exceed 20 billion dollars annually. Therefore, one of the main objectives of all container shipping companies is to reduce the ECR and accordingly the ECR costs.

Empty container repositioning (ECR) costs increase the total operations costs of shipping companies and do not provide any added value to customers. No matter how the ECR costs are defined and classified, these costs have a crucial act in container shipping. With a more concrete expression; it is required to decrease and regularly monitor the ECR costs in terms of providing profitability and advantage in the global competitive environment.

Since ECR causes an increase in overall traffic leading to high carbon emissions, they also affect the society and environment (Flämig et al., p.49). Therefore, optimal planning of ECR would indirectly contribute to reduced congestion and environmental pollution (Hjortnaes et al., 2017).

ECR has been a point of interest in the academic world. There are significant number of studies on ECR in the literature. Most of the studies focus on the optimization of ECR resulting from container imbalances. New strategies and methods on the management of ECR have been proposed in these studies.

This study examines the researches and trends in empty container repositioning (ECR) practices and reveals the missing research areas in the literature. It discusses the mathematical models developed in the literature and addresses real-life applications of the container shipping companies. The study also emphasizes how the opportunities in technological development can be used in ECR practices and provides suggestions for research topics that can be studied in the light of current trends in container shipping. The main purpose of the study is to reveal underlying studies on ECR in the literature and put forward research and real-life application opportunities in the field of ECR. In this respect, this study can be considered as a literature review update on ECR. Through this study, companies in the container shipping industry will be able to recognize the models and approaches introduced in the literature to overcome the ECR costs. On the other hand, researchers and scholars will be able to see in which field on the ECR they can make scientific researches.

In the preparation of this study, following guidelines were applied: First of all, the keywords used for the search were named. Key words such as 'container logistics', 'container management', 'empty container movement', 'empty container repositioning', 'empty container optimization', 'costs in container shipping', 'pricing in container shipping', 'cost optimization in container shipping', 'cost management in maritime logistics', 'container sharing' were searched in academic databases, journals and scholarly search engines. As a result of these searches, articles related to the study's topic were selected. Moreover, the references of the articles were verified to find other resources related to the study's topic. Sector reports and online news web-sites such as Lloyd's List, World Maritime News were also used for some topics. Furthermore, the books that stand out in terms of maritime transportation, container shipping and logistics were referred as important resources as well.

In addition to reviewing the literature, the authors' practical and professional experiences in 
the container shipping industry have also been taken into consideration in putting forward the current situation, trends, problems and suggestions in the industry. The titles in the next sections have been specifically developed in light of the practices in the industry and they refer to issues that have not been dealt much in other studies. As there are very few studies in the literature on the topics covered in some sections, real life practices on these topics have been explained and the importance of these implementations has been put forward.

The outline of the paper is as follows: Section 2 explains the management of ECR according to the decision levels. Section 3 introduces the actors in ECR. Section 4 examines the studies involving mathematical models on ECR. Section 5 discusses the cost and pricing issues in ECR. Section 6 presents the strategies to reduce ECR and demonstrates the studies in this topic. Section 7 highlights the importance of Information Technology (IT) in ECR. Section 8 concludes the study by mentioning some future research directions on ECR.

\section{Management of Empty Container Repositioning}

Other than the goods transported inside of it, a container itself is also an asset that needs to be dealt with. The phenomenon of ECR has attracted considerable attention in academic world. Jarke (1981) made the first review on container management problem and highlighted the importance of efficient container transportation logistics. Dejax et al. (1987) conducted a literature review on ECR. The author presented the trends in ECR and addressed the prominent models developed in the literature for the solution of problems on ECR.

According to the decision levels, management of empty containers are handled in three levels; strategic, tactical and operational level. Decisions such as the determination of container fleet size and long-term lease agreements are taken by the shipping lines at strategic level (Braekers et al., 2011). Vessel route planning, agreements with third-party transportation providers, terminals and depots can be considered as tactical decisions related to management of empty containers. Strategic and tactical decision are directly taken by the top management of the shipping companies. Operational decisions are usually carried out by local agencies and regional offices of the shipping companies and mainly involve short-term plans such as distribution of empty containers from surplus locations to deficit locations considering vessels' arrivals, departures and capacities on regular basis.

ECR are mainly treated as logistics activities in liner shipping and carried out by the logistics departments of shipping companies (Baird, 2015, p. 190). In terms of geographical planning level, ECR take place at four scales; global, interregional, intraregional and local (Theofanis $\&$ Boile, 2008). The global level includes intercontinental ECR and is directly carried out by the logistics headquarters of the container shipping companies. Sending the surplus empty containers from North America to Asia can be a good example for the ECR at global level. The interregional level includes the ECR in a large area and is usually carried out by the logistics departments at the headquarters of liner carriers as well. Nevertheless, depending on the proximity of the regions and number of containers, ECR at interregional level can also be executed by the regional offices of the liner carriers. Repositioning the surplus empty containers from North Europe to North Africa can be regarded as interregional ECR. The intraregional level involves the ECR between the locations within the same region, and the 
logistics departments in the regional offices are in charge of such operations. ECR between Istanbul and Odessa in the Black Sea Region can be considered as this type of planning level. ECR at local level occurs between the depots and terminals in the same location. For example, managing the movements and storage of empty containers in Istanbul are at such a level of planning. This level of operations is mainly carried out by the local agencies of the liner carriers.

Kolar et al. (2018) examined the behavior of ocean carriers in terms of ECR in a landlocked hinterland, in Czech Republic. In that study, it was seen that the ocean carriers have different management strategies according to the decision levels. The investigation of planning levels is important in terms of understanding the occurrence and patterns of ECR, and therefore in terms of the designation the ECR costs. So that it can be determined in which region, location or service line the costs will be allocated.

Kuzmicz and Pesch (2018) made a detailed literature review on ECR. Taking into account the OBOR initiative, the authors discussed how the ECR will be affected as a result of the trade imbalance that arises due to container flow between China and Europe.

\section{Actors in Empty Container Repositioning}

Liner carriers, which are the container shipping companies, are the most important actors in ECR in terms of expenditures and duration of container usage. Besides the liner carriers, ECR also have significant effects on other actors in container shipping industry such as other carriers, terminal and depot operators, inland carriers, leasing companies, shippers and consignees (Lun et al., 2010, p.151).

For other carriers or third-party vessel operators, transportation of empty containers means lower income as the freight rates for them are lower than the transportation rates of full containers. Similarly, for inland carriers, transportation of empty containers also means little profit. Nevertheless, in case of limited weight and idle capacities on the vessels or inland transportation vehicles, transportation providers benefit from the shipment of empty containers.

Compared to full containers, terminal operators also gain lower profit from empty container handlings and storage. On the other hand, a large number of empty containers cause congestion and inefficiency at terminals. For this reason, some terminal operators do not accept empty container deliveries at terminal or charges high storage costs to customers. Accordingly, many liner carriers prefer to use off-dock depots. The depot operators are important partners of carriers as they mostly make money from empty container handling, storage and repair.

Leasing companies are also important actors in the container shipping industry. They own a share of $41-49 \%$ of the total container fleet (Leeuwen, 2016). Carriers usually make long-term leasing agreements with the leasing companies. Nevertheless, depending on trade imbalances, short-term leasing agreements take place as well. In general, carriers prefer to off-hire containers in surplus locations and on-hire in deficit locations. To avoid the commercial exploitation, leasing companies put some quotas and restrictions to the carriers in 
many surplus locations (Theofanis \& Boile, 2009). They can also lease the returned containers to another carriers in the same locations or reposition them to other locations of high demand. The relationship between the shipping companies and container leasing companies is a very broad and different issue that needs to be investigated separately.

Shippers and consignees in container shipping are usually the transportation providers such as freight forwarders or other carriers, but can also be the direct seller or buyer of the goods that are carried in the containers. In general, they are responsible for the pick up of empty containers to be filled at the port of origin, and for the returning of empty containers at the port of destination. Namely, they also take important place in ECR because of the direct connections with liner carriers.

\section{Optimization Models in Empty Container Repositioning}

Researches in the literature have usually examined the problem of ECR in terms of finding the optimum empty container distribution plan (Hajeeh \& Behbehani 2011). Some studies have taken into account that shipping companies use third-party vessel operators to transport their empty containers, whereas some focused on the problem through the assumptions that shipping companies have their own vessels by considering vessel capacity as the full and empty containers are carried together. This section discusses the studies of deterministic and stochastic mathematical models developed on ECR.

\subsection{Deterministic Models in Empty Container Repositioning}

Most of the studies in the literature have addressed the problem of ECR deterministically. That is, it is taken into account that the parameters in ECR decisions are strictly known. The first study on ECR in the literature was conducted by Potts (1970). The author solved the problem of ECR using the standard out-of-kilter algorithm. White (1972) presented an algorithm that considers the distribution of empty containers as a minimum-cost flow network problem. Ermolev et al. (1976) introduced a network model for ECR by taking into account transportation and container leasing costs. In his Phd thesis, Florez (1986) formulated a dynamic container allocation model for ECR and container leasing. The author introduced a dynamic transshipment network model which is solved by using two linear programming (LP) algorithms.

One of the first decision support systems (DSS) based on the network optimization models on empty container distribution was proposed in the paper of Shen and Khoong (1995) where a single container type and leasing decisions were assumed. Nevertheless, the technical aspects about the optimization models were not addressed in the paper. Choong et al. (2002) examined ECR at tactical level to analyze planning horizon effect on ECR and introduced an integer programming model that minimizes total ECR costs.

Wang and Wang (2007) studied the ECR problem for inland transportation. They developed an integer linear programming (ILP) model to minimize ECR costs. The model in that study also considers the container shortage and leasing costs. Shintani et al. (2007) addressed the design of container liner shipping service networks by taking into account the ECR. The authors handled vessel deployment and ECR together and developed a genetic algorithm 
based heuristic for the solution of the problem. The numerical experiments in that study proved that the simultaneous consideration of vessel deployment and ECR can provide better results than handling vessel deployment and ECR one by one.

Feng and Chang (2008) studied the ECR problem in terms of safety stock management. The authors developed a two-step approach to minimize the ECR costs. The first stage determines the empty container stock and the second stage finds the optimum distribution plan of empty containers. Bandeira et al. (2009) developed a DSS which considers the distribution of empty and full containers. Additional to the integrated solution of empty and full containers, the authors also provided analysis' for the customer service level in terms of transportation time and time of order completion.

Dang et al. (2012) examined repositioning of empty containers in a port area with multiple depots. The authors developed a simulation model and four heuristics to find optimal inventory policies for empty containers. Dong and Song (2012) studied the ECR problem in a shipping network with multiple service routes in detail. They introduced two solution methods to minimize the total ECR costs. The first method is a shortest-path based integer programming (IP) model and the second method is a two-stage heuristic-rule based IP model. Numerical results showed that both of the solution methods perform better than the real-life practices.

Furio et al. (2013) investigated ECR at local level and considered street-turn applications in the hinterland of Valencia. The authors developed a DSS based on an optimization model that minimizes total costs of ECR including storage costs at terminals and depots. The computational results based on the real data showed that the model developed in the study significantly reduces the ECR costs.

Moon et al. (2013) examined the comparison of the repositioning costs of foldable containers with standard containers. Three mathematical models were developed in the study to minimize the total costs including container purchasing cost, repositioning cost, folding/unfolding cost and storage cost. Two heuristics were also developed in the study to solve the mathematical models. Numerical results in that study showed the economic practicality of foldable containers. Myung and Moon (2014) developed a model for the repositioning of standard and foldable empty containers. The authors represented the ECR problem as a minimum cost network problem and showed that the minimum cost network flow algorithm finds the optimal solution.

Zhang and Facanha (2014) analyzed empty container operations plans of a shipping line and proposed some strategies to reduce the total ECR costs in the transpasific services. Çağlar and Esmer (2015) carried out a qualitative study on the ECR problem in Turkey. The authors conducted in-depth interviews with port authorities and agencies of liner carriers in Turkey. They discussed the issues arising from ECR and offered short and long-term solutions.

Huang et al. (2015) studied network design and cargo routing problem and proposed a mixed integer linear programming (MILP) model that minimizes total operating costs. The proposed model does not take into account different type of containers but only total number of TEUs. 
The numerical results based on the real data showed promising results in terms vessel capacity utilization. Akyüz and Lee (2016) considered a simultaneous service type assignment and container routing problem. Besides the vessel deployment and speed optimization, ECR were also taken into account in the study. The authors formulated a MILP model that minimizes total vessel deployment costs in liner shipping. For the solution of the problem, a column generation procedure and a branch and bound algorithm were developed. Thanks to these solution approaches, the simultaneous service type assignment and container routing problem can be solved in a reasonable time.

Xie at al. (2017) studied empty container management from a game theoretical point of view. The authors formulated two models -a centralized model and a decentralized model- for an intermodal transportation system that consists of one rail firm and one liner carrier, and obtained optimal policies for both models. Hjortnaes et al. (2017) developed a deterministic LP model for the minimization of ECR costs by considering container repair operations in a port area. The model was tested with the real data and provided promising results.

\subsection{Stochastic Models in Empty Container Repositioning}

Although many studies in the literature dealt with ECR in a deterministic way, there are many uncertainties in real life applications. As the parties in container shipping have different purposes, vessel arrivals, vessel space and weight capacities, customer demands can change at any time. Especially, it is crucial to meet customer demand on time in liner shipping. Studies have been carried out in the literature that take into account the uncertainties of real-life applications in ECR.

Lai et al. (1995) examined ECR problem and proposed a planning approach to real-life applications of a Hong-Kong based shipping company. The authors considered the uncertainty in container demand and developed a simulation model of company's operations, and introduced a two-step heuristic in accordance with company's ECR policy to minimize total operation costs including handling, storage, short-term leasing and idling cost of empty containers. Based on the real data, the results of the study demonstrated that their approach could provide high operational cost savings to the company. Cheung and Chen (1998) formulated a two-stage stochastic network model which considers the uncertainty in vessel capacities and number of empty containers in the surplus and deficit locations.

Li et al. (2004) discussed the management of empty containers in a seaport from an inventory problem point of view by considering positive and negative container demands. This work was extended in a latter paper which handles the same problem for a multi-port case (Li et al., 2007). The authors also developed a heuristic algorithm to compute the feasible inventory policies. The numerical examples in the paper showed that the heuristic could provide very close results to the optimal solutions.

Song (2006) investigated the optimal policy for ECR in a periodic-review shuttle service. Random customer demand were taken into account in that study using the Markov decision process to find the optimal stationary policy of ECR. In addition to storage and transportation costs, the model proposed in the study considers the container leasing costs as well. 


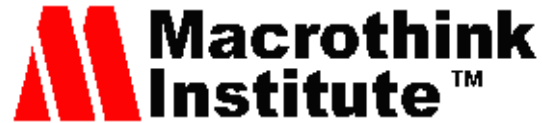

Business and Management Horizons

ISSN 2326-0297

2019, Vol. 7, No. 1

Some studies handled dynamic repositioning of empty containers considering the uncertainties. Crainic et al. (1993) proposed both deterministic and stochastic dynamic network models for inland repositioning of empty containers at tactical level. Lam et al. (2007) introduced a dynamic stochastic model for ECR problem in a two-ports two-voyages system. Erera et al. (2009) developed a robust optimization model for dynamic ECR. All these studies have shown promising results in reducing ECR costs.

Dong and Song (2009) introduced a simulation-based evolutionary algorithm to minimize the total ECR costs of a shipping line which has its own vessels. In their model, all type of container sizes and full containers are also considered which directly influence empty container allocation on the vessels in terms of TEU capacity. The strength of the model is to include almost all the cost items such as transportation cost, storage cost, container handling cost, penalty cost for unmet demands in ECR.

Francesco et al. (2009) handled ECR problem under uncertain parameters. They proposed a mathematical model to minimize the ECR costs by considering transportation, storage and handling costs in a shipping network. The computational results based on the historical data of a shipping company showed that the proposed mathematical model provides better repositioning plans for empty containers in comparison to the deterministic ones. Long et al. (2012) examined the ECR problem at the operational level and formulated a two-stage stochastic programming model which minimizes the ECR costs. Their study handles with the uncertainties in the demand and supply of empty containers, available space and weight capacity for empty containers on the vessels. The authors used sample average approximation method to solve the stochastic problem. Moreover, for the solution of the large-scale problems, two heuristics algorithms were applied in the same study. The numerical results demonstrated that the algorithms provide good solutions and can significantly reduce the ECR costs.

Wang and Tang (2010) studied the container transportation problem considering full and empty containers only for maritime transportation under uncertain container supply. The authors proposed a chance-constraint programming model which is transformed into an integer programming model which has an objective of maximizing the total profit. The numerical examples of that study showed promising results. Francesco et al. (2013) studied the ECR problem considering disruptions of port calls. They developed a stochastic programming model including different scenarios regarding the uncertainty in port disruptions. The computational results in the study proved the effectiveness of the model which solves even the large-scale problems in a few minutes in CPLEX optimization software.

Mittal et al. (2013) investigated the ECR problem in terms of deciding for opening new inland depots in a service network. In their study, the authors considered the uncertainty in container demand and supply, and developed a two stage stochastic programming model with recourse that minimizes ECR costs to find the optimum locations of the inland depots to be opened in a 10 year time horizon.

Wong et al. (2015) developed a yield-based container repositioning framework based on a 
constraint LP model. The model considers the uncertainty in the upsurge container demand. The results of the proposed model in the study provided satisfying container repositioning plans and can be used as a decision support tool for real life applications.

\section{Cost Estimation in Empty Container Repositioning}

Pricing in container shipping is a broad topic to be examined on its own. As Slack and Gouvernal (2011) stated, the structure of container freight rates have become much more complex. When offering a freight rate, all the costs should be taken into consideration in order to see how much profit or loss will be made. So, it is necessary to make an accurate cost analysis to offer a lucrative freight rate. In this regard, pricing and cost analysis issues are at the center of container shipping. However, this subject has received little attention in the literature. Similarly, estimation of ECR costs has been little studied in the literature as well. Along with other costs, ECR costs should also be taken into account when determining an accurate freight price. To put it more precisely, costs of ECR incurred before the shipment, and costs to be generated after the return of container from the consignee at the port of destination must also be added to the shipment price.

Slack and Gouvernal (2011) examined the effect of surcharges on container freight rates. The authors revealed the role of surcharges such as terminal handling charges (THC), bunker adjustment factor (BAF) and currency adjustment factor (CAF) on a real data in detail. Although the ECR costs were mentioned as logistical imbalances surcharges in their paper, the authors did not elaborate on this issue.

One of the first studies on revenue management in container liner shipping was conducted by Wang et al. (2015). The authors developed a bi-level optimization model to maximize the expected profit of a shipping line. The analyzes in the study revealed beneficial results for pricing decisions of the managers. Liu and Yang (2015) studied slot allocation of full and empty containers on a sea-rail transport line in terms of revenue management. The authors introduced a two stage model where the first stage finds the optimal slot allocation and the second stage obtains the optimal pricing strategy. Numerical results showed that the solution approach developed in the paper can be used as an accurate tool in pricing decisions.

$\mathrm{Xu}$ et al. (2015) proposed a mathematical model to analyze how the pricing decisions are determined depending on the ECR costs. Their study deals with a transportation service that consists of one carrier and two freight forwarders between two ports in order to observe their pricing policies on the service.

Goh and Chan (2016) studied the impact of empty container back haul costs in the inland of USA. They proposed a solution approach to compute the shadow prices of ECR costs by using Lagrangian and Kuhn-Tucker methods. The numerical results in the study demonstrated that the solution approach can help the carriers at the operational level to see the effect of ECR costs on marginal costs in terms of whether or not to accept the spot shipments.

ECR costs have also not been studied much in terms of transaction costs. Lopez (2003) examined the inland repositioning of empty containers in the USA from ocean carriers point of view. The author revealed the commercial relationships and characteristics of bargaining 
between ocean carriers and inland transportation providers. According to which conditions the contracts and costs in rail and road transportation may change, was clearly analyzed in the study.

Lee and Song (2017) presented an overview and research opportunities in global container transportation where they also discussed ECR from two perspectives: quantity decision and cost estimation. Quantity decision refers to the traditional optimization methods to decide from where to where, when and how many empty containers need to be sent in a planning horizon. This perspective has been quite studied in the literature. On the other hand, cost estimation is a viewpoint of how the ECR costs would be taken into account in terms of pricing decisions. Although the authors emphasized the importance of this, they did not provide detailed information on that issue. Likewise, they did not refer to any study in this regard as well.

Fazi and Roodbergen (2018) addressed the importance of demurrage and detention costs in container hinterland transportation. The authors introduced a mathematical model and a heuristic taking into account demurrage and detention costs in hinterland container supply chain and showed that better decisions and transport efficiency can be achieved according to different demurrage and detention policies. Yu et al. (2018) dealt with the detention costs in the hinterland container transportation system. A two-stage game model was proposed in the paper which considers detention decisions of ocean carriers and hinterland container operators.

There is still no single study in the literature on the applications of accounting techniques or costing methods in maritime transportation. However, maritime transportation, especially container shipping, is a very suitable field for costing applications. Because container transportation is a cellular type of transportation and a large number of customers are serviced on the same vessel, it is an extremely attractive issue not only for the costing approaches, but also for the pricing researches. In this context, the effect of ECR costs on freight price can also be obtained more accurately with costing methods.

\section{Strategies to Reduce Empty Container Repositioning}

One of the ways to reduce ECR is container sharing or exchange. It can also be regarded as a sub-lease in practice. Depending on the commercial imbalances, some shipping companies may have surplus containers in a location whereas some others have deficit for the same type of container in the same location, or vice versa. A shipping company which has surplus containers in a location, instead of sending these surplus containers to other locations, can give them to other shipping companies which are short of containers within the same location. A shipping company receiving and using the containers will return these containers in a predetermined location where they are required by the shipping company that released these containers in the initial location. In this way, both of the shipping companies will reduce ECR and save on ECR costs.

The topic of container sharing among the shipping companies has been rarely studied in the literature. In a report on empty container logistics, Le (2003) addressed the importance of 
container sharing and coordination among shipping companies. Song (2007) showed that a collaborative strategy of container management can provide high cost savings especially for the shipping companies with smaller container fleet size.

Song and Carter (2009) studied the options of reducing ECR costs in liner shipping from two aspects; through an effective management of container fleet and sharing containers with other shipping companies. The authors demonstrated that worldwide coordination and sharing containers with other companies can significantly reduce the ECR costs. Zheng et al. (2015) examined the ECR problem taking into account container sharing among shipping companies. The authors introduced a two-stage optimization approach to reduce ECR. As expected, the numerical results in the paper showed that the shipping companies can benefit from container sharing with each other.

Real-life applications and literature studies show that container sharing reduces ECR and provide cost savings. However, there are some difficulties to implement the sharing process of the containers with other shipping companies. Actually, most of the shipping companies would always prefer to share the containers if there were no bureaucratic, complex documentation and operation processes. Since all the national laws and international law consider an empty container itself as an asset, shipping companies must deal with the documentation process and make official agreements with each other to share the containers. The type of the agreement is another issue that should be considered. For example, some shipping companies allow sharing their container free for 30 days and after 30 days charge 2 USD per day for each container, whereas some shipping companies charge costs already from the beginning. Namely, while sharing of containers decrease the ECR costs, it may lead to high sub-lease costs for the shipping companies. Eventually, taking into consideration the potential challenges in terms of communication and coordination for the delivery of containers in the predetermined location and depot, management and control of the shared containers cause the shipping companies to exert extra efforts. Nevertheless, in parallel with the coordination and cooperation such as vessel sharing agreements in the industry, container sharing between the shipping companies will also increase in the near future.

A similar method to container sharing is the container cabotage. In case of container cabotage, the cabotage company, which is a third party carrier or an intermediary company, borrows the container from the shipping company to return in a location where the shipping company demands it. The cabotage company usually uses the container for a single one way trip. This procedure can also be regarded as a sub-lease, and the lending time of the container may vary depending on the agreement between the cabotage company and shipping company.

One of the ways that shipping companies want to implement to reduce their ECR and costs is the street turn approach which is also called triangulation. The benefits of the street turn application were also revealed by Jula et al. (2003) and Le (2003). Figure 2 shows the normal container flow and street turn approach in a location. In situation a, a local consignee, who is the importer of the full container, receives the full container from the terminal and returns it to the shipping company at the terminal as empty. A local shipper pick ups the empty container from the terminal to fill it. After the container is filled with the cargo, the local 


\section{I Macrothink}

Business and Management Horizons

ISSN 2326-0297

2019, Vol. 7, No. 1

shipper brings it to terminal to be loaded on the vessel. Namely, the local shipper becomes the exporter of the full container. As can be seen, transporting the empty container to the terminal, accepting and storing at the terminal, then moving it from the terminal to the local shipper's place caused costs in this cycle. The costs, which are incurred when the containers are under control of the shipping company, are covered by the shipping company. Other operation costs are covered by the consignee and the shipper. Namely, in liner shipping applications, the cost of accepting and storing the container at the terminal is generally borne by the shipping company.

In the situation $b$, after the unstuffing process of the container, the local consignee delivers the empty container directly to the local shipper instead of returning it to the shipping company at the terminal. Thus, both the consignee and shipper save on empty container transportation costs. Moreover, the shipper also avoids empty container pick up costs at the terminal. The shipping company that provides the liner services prevents empty container acceptance and storage costs at the terminal. It reduces its documentation work as well. More importantly, the shipping company provides added value to its customers, who are the local consignee and shipper, by reducing their ECR and costs.

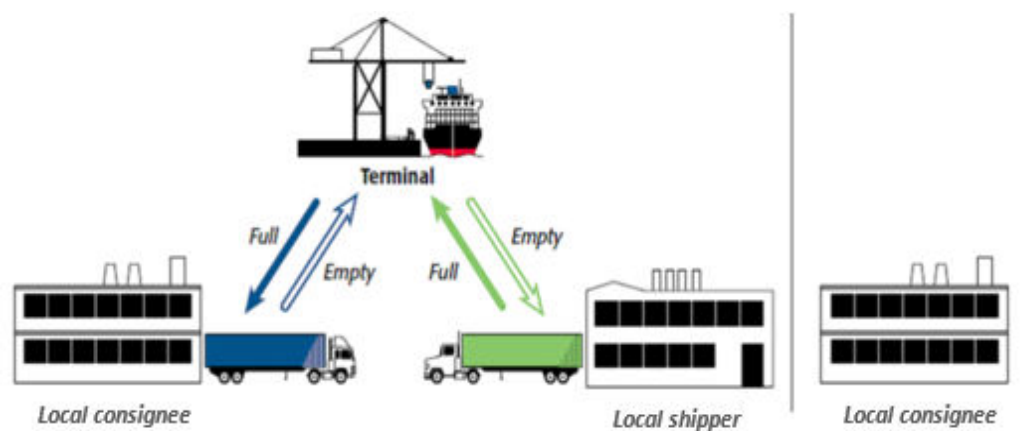

(a)

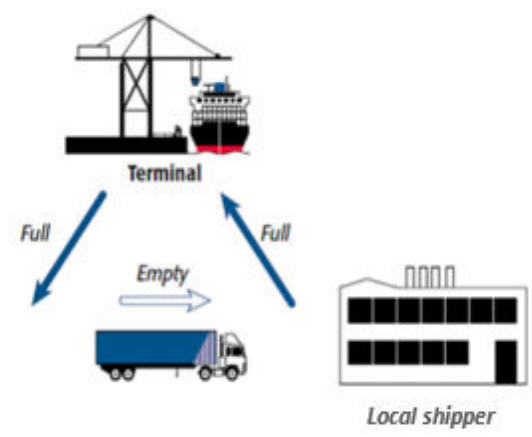

(b)

Figure 2. Street turn application (Adapted from http://www.hbs.edu, Retrieved June 3, 2018)

Although the street turn approach provides cost savings, it is quite difficult to implement it in practice. First of all, there must be a systematic and rapid communication network between the shipping company and its customers. Secondly, problems can arise on determining the parties responsible for container damage and inspection. From this point of view, it may be a good strategy for the shipping companies using the same depots with their customers or to work with the depots that are located close to their customers and provide high quality services for container cleaning and damage.

The emergence of foldable containers can be considered as an innovation in the container shipping industry. Foldable containers have been developed for the purpose of eliminating congestion at terminals, saving space at depots and terminals, and avoiding high movement costs caused by the standard empty containers (Konings \& Thijs, 2001). In their study, Shintani et al. (2010) developed an integer linear programming model and found that the use of foldable containers provides more cost savings than standard containers. Wang et al. (2017) examined the effect of standard and foldable empty containers on ship type decision. The authors stated that foldable containers reduce the repositioning cost, however, using foldable 
containers can increase the total costs due to high long-term leasing costs. Although these studies in the literature demonstrated that using foldable containers can save on ECR costs than using standard containers, foldable containers have not attracted much attention in the container shipping industry.

Substitution between the container types can also be a good application to reduce the ECR and costs in liner shipping. Shipping companies can handle this kind of application in their own way without needing the coordination of other companies. Nevertheless, shipping companies should perform a very detailed and accurate profit/loss analysis in case of container substitution. Studies in the literature on that topic are also scarce. In a study, Chang et al. (2008) developed a heuristic method for the solution of container substitution problem. Numerical results in that study showed that the proposed method could be effectively used by the shipping companies.

\section{Importance of Information Technologies in Empty Container Repositioning}

Information and Technology (IT) is a function that has gained more importance in business. There is no technology that has succeeded in rapidly influencing shipping industry as much as IT. Indeed, one of the factors that contributed most to the revolution created by the container in transportation is the developments in computer technologies. Thanks to the introduction of microchips, since the early 1970s, computer and container shipping have shown a parallel development. The development of computer technologies accelerated the development of IT, thus providing a unique dimension to container shipping.

Bensghir (1996) describes IT as a technology that enables faster and more efficient operations and transactions such as recording, storing and generating information through the processing of data; accessing, storing and transmitting this information in line with the purpose of the company. In other words, IT allows the collection, processing, storage, submission and transferring of the information in a more accurate way. Information and data for large companies are the two most valuable corporate assets today. To demonstrate the significance of this in the shipping industry, Detlef Trefzger, CEO of Kuehne and Nagel, stated: "Data is the raw material for our new currency, which is information, based on real time data to enable our customers, partners and ourselves to take the right decisions". Namely, IT has made a great contribution to the establishment of new opportunities and new business relationships.

In order to improve their service quality and increase the profitability and competitiveness, shipping companies should closely follow the developments in IT and use management information systems (MIS) such DSSs, enterprise resource planning (ERP) and business intelligence softwares. When logistical activities are supported by such advanced softwares, shipping companies can achieve success in data collection and use of these data in planning, control and decision making functions. The use of IT is also essential for the management of ECR. Like for many logistics functions, storage and processing of data, real-time communication capabilities, report generation, complex analytical tools, but simple usage are also required for the management of ECR. Many shipping companies already use advanced business intelligence softwares. These softwares are very useful in terms of tracking of containers, tracking and controlling of operations, job orders and invoices and for their 
reporting.

Although the problem of ECR has been studied extensively in the literature, the mathematical models developed in the literature studies are not applied much in real life. One of the reason for this is the difficulty in the adaptation of the models and external optimization softwares to the shipping companys' systems. Another reason is the high purchasing and using cost of the softwares. The former Chilean shipping company Compañía Sud Americana de Vapores (CSAV) developed a system called Empty Container Optimization (ECO) that optimizes ECR by integrating operational and commercial decisions at its all regional offices (Epstein et al., 2012). However, there is no clear information about the availability, effectivity and sustainability of this system. IBM has a software product for the optimization of ECR which works with CPLEX Optimization Solver base. Although the price of this product seems high, its use can provide much more cost savings to the shipping companies. There are also various softwares on the market for solving many other problems related to operations and logistics management. The approaches in those softwares can also be adapted to container shipping industry, particularly to ECR. Nowadays, many shipping companies are already more concerned with analytics and have begun to develop their own business intelligences and optimization softwares by spending large amounts of money.

In addition to all of the above, Industry 4.0 which based on digitalization phenomenology, will also have a very important influence on the management of ECR (UNCTAD, 2016b). According to a report of Boston Consulting Group (BCG), seven digital trends will transform the container shipping industry: E-platforms, Advanced Analytics, Internet of Things, Artificial Intelligence, Autonomous Vessels and Robotics, Blockchain, Cyber Security. Here, "Advanced Analytics" stands out especially in terms of planning and operations, and this will have a significant impact on ECR (BCG, 2018). Through digitalization, ECR will be tracked more accurately and more robust container inventory information will be obtained. Moreover, better empty container distribution plans will be made by using new developed softwares based on mathematical models and algorithms. The costs of the operations related to ECR will be better and faster analyzed, and more accurate pricing will be ensured. Consequently, better decisions will be made through the instant and constant updated data and information.

\section{Conclusion}

Container shipping industry struggle with the problem of trade imbalances which cause too much ECR and costs. This issue in container imbalances have been interested in the academic world as well. Many studies developed new strategies and offered new methods to solve this problem. In this study, prominent studies related to ECR were discussed and issues not studied in the literature were emphasized. This study have demonstrated that some models developed in the literature can be easily applied in practical life to help shipping companies, while some applications in container shipping industry need to be examined in detail from a scientific point of view.

Management of ECR has been studied at many levels in the literature. Most of the studies have addressed methods for optimal empty container distribution planning and considered single container type. Likewise, operations research and other optimization methods are 
extensively used in the researches. The objective function in the vast majority of studies is to minimize the total ECR costs. The problems were usually solved by the variations of LP models. In some studies, advanced optimization methods such as column generation, cutting plane algorithms and heuristics have been developed to solve large-scale problems. In the majority of studies, ECR have been handled from a deterministic perspective. But there are many uncertainties in real-life applications of ECR. Thus, some studies in the literature take uncertainties into consideration for the solution approaches on ECR. Despite the sufficient number of academic studies where new approaches and models developed on the management of ECR, there are not many practical applications of these approaches and models used by the shipping companies in real life.

One of the ways to reduce the ECR is the street turn application. Its implementation is quite difficult because it requires immediate and instant coordination and cooperation between the shipping companies and customers. However, the application of the street turn approach will be definitely easier in the future thanks to the advanced IT systems. Using foldable containers is another way to reduce the ECR and costs. Indeed, researches in the literature have revealed this fact.

The topic of container sharing has been studied quite less in the literature. Nevertheless, these small number of studies revealed evidences that having an efficient coordination and cooperation with other shipping companies in terms of sharing the containers can significantly reduce the ECR and provide cost savings. Another less studied topic in the literature is container substitution. Although container substitution can be considered a good application in terms of reducing ECR in liner shipping, studies on container substitution are also very limited in the literature. Accordingly, future researches on container sharing and substitution will shed light on real-life applications in ECR.

Even though the models and strategies developed in the studies reduce the costs of ECR, shipping companies do not escape from these costs altogether. These costs have a direct influence on the location choices of cargo and freight prices. Although this is known by the shipping companies and researchers, there is no single study in the literature on how to accurately evaluate and allocate the ECR costs. In fact, there are also few studies on pricing and revenue management in container shipping. The analysis of ECR costs has never been addressed in these studies as well. Therefore, there is a great need for new studies on pricing and costing methods related to ECR.

One of the other subjects that have not been studied in the literature on ECR is multi-objective decision making which is actually a very popular and highly studied topic in logistics and operations management. Many objectives in real-life applications of ECR can conflict with each other. On the other hand, as ECR constitute a small part of container shipping, the development of models that take into account other operations and different objectives will lead to more accurate decisions not only in ECR, but also in the whole container shipping system. In this respect, researches to be carried out in this area will attract a lot of attention.

The use of sophisticated IT systems is essential for the management of ECR. Advanced IT 
systems have enabled more accurate and faster follow-up of ECR, as well as provided rapid information flow and electronic data interchange (EDI). Nevertheless, IT is not used with the full potential in the container shipping industry. Just as it is in many other sectors, container shipping industry will also be more digital in the future. Advanced MIS based on robust mathematical models and algorithms will be used more often and effectively within the companies. Consequently, continuous improvement in the field of digitalization and IT systems will lead to smoother processing in all aspects of container shipping. Although there is still no concrete study in the literature on this subject, the number of studies on the effect of digitalization will increase considerably in the future.

\section{Acknowledgments}

The authors would like to thank the anonymous referees for their valuable comments and suggestions to improve the paper.

\section{References}

Akyüz, M. H., \& Lee, C. Y. (2016). Service type assignment and container routing with transit time constraints and empty container repositioning for liner shipping service networks. Transportation Research Part B: Methodological, 88, 46-71. https://doi.org/10.1016/j.trb.2016.02.007

Baird, A. J. (2015). Logistics strategy in container shipping. In Maritime Logistics: A Guide to Contemporary Shipping and Port Management (2nd ed., pp. 171-192). London: Kogan Page Limited.

Bandeira, D. L., Becker, J. L., \& Borenstein, D. (2009). A DSS for integrated distribution of empty and full containers, Decision Support Systems, 47, 383-397. https://doi.org/10.1016/j.dss.2009.04.003

BCG. (2018). The Digital Imperative in Container Shipping. Retrieved from https://www.bcg.com/en-tr/publications/2018/digital-imperative-container-shipping.aspx

Bensghir, T. K. (1996). Information technology and organizational change. TODAE Publications, Ankara.

Braekers, K., Janssens, G. K., \& Caris, A. (2011). Challenges in Managing Empty Container Movements at Multiple Planning Levels. Transport Reviews, 31(6), 681-798. https://doi.org/10.1080/01441647.2011.584979

Çağlar, T., \& Esmer, S. (2015). Türkiye'de Boş Konteynerlerin Yeniden Konumlandırılması Sorunu Üzerine Nitel Bir Araştırma. Mustafa Kemal Üniversitesi Sosyal Bilimler Enstitüsü Dergisi, 12(31), 242-256.

Chang, H., Jula, H., Chassiakos, A., \& Ioannou, P. (2008). A heuristic solution for the empty container substitution problem. Transportation Research Part E: Logistics and Transportation Review, 44(29), 203-216. https://doi.org/10.1016/j.tre.2007.07.001

Cheung, R. K., \& Chen, C. Y. (1998). A Two-Stage Stochastic Network Model and Solutions 
Methods for the Dynamic Empty Container Allocation Problem. Transportation Science, 32(2), 142-162. https://doi.org/10.1287/trsc.32.2.142

Choong, S. T., Cole, M. H., \& Kutanoğlu, E. (2002). Empty container management for intermodal transportation networks. Transportation Research, Part E, 38(6), 423-438. https://doi.org/10.1016/S1366-5545(02)00018-2

Crainic, T. G., Gendreau, M., \& Dejax, P. (1993). Dynamic and stochastic models for the allocation of empty containers. Operations Research, 41(1), 102-126. https://doi.org/10.1287/opre.41.1.102

Dang, Q. V., Yun, W. Y., \& Kopfer, H. (2012). Positioning empty containers under dependent demand process. Computers \& Industrial Engineering, 62, 708-715. https://doi.org/10.1016/j.cie.2011.11.021

Dejax, P. J., \& Crainic, T. G. (1987). A review of empty flows and fleet management models in freight transportation. Transportation Science, 21(4), 227-247. https://doi.org/10.1287/trsc.21.4.227

Dong, J., \& Song, D. (2009). Container fleet sizing and empty repositioning in liner shipping

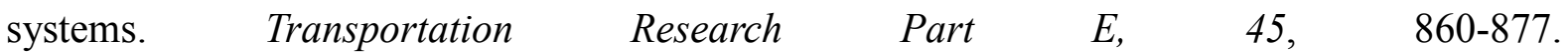
https://doi.org/10.1016/j.tre.2009.05.001

Dong, J., \& Song, D. (2012). Cargo routing and empty container repositioning in multiple shipping service routes. Transportation Research Part B, 46, 1556-1575. https://doi.org/10.1016/j.trb.2012.08.003

Epstein et al. (2012). A Strategic Empty Container Logistics Optimization. Interfaces, 42(1), 5-16. https://doi.org/10.1287/inte.1110.0611

Erera, A. L., Morales, J. C., \& Savelsbergh, M. (2009). Robust optimization for empty repositioning problems. Operations Research, 57(2), 468-483. https://doi.org/10.1287/opre.1080.0650

Ermolev, Y. M., Krivets, T. A., \& Petukhov, V. S. (1976). Planning of shipping empty seaborne containers. Cybernetics, 12(4), 644-646. https://doi.org/10.1007/BF01070404

Fazi, S., Roodbergen, K. J. (2018). Effects of demurrage and detention regimes on dry-port based inland container transport. Transportation Research Part C, 89, 1-18.

Feng, C. M., \& Chang, C. H. (2008). Empty container reposition planning for intra-Asia liner shipping. Maritime Policy \& Management, 35(5), 469-489. https://doi.org/10.1080/03088830802352111

Flämig, H., Wolff, J., \& Herz, N. (2011). A hotspot for empty flows. Baltic Transport Journal, 4, 48-49.

Florez, H. (1986). Empty Container Repositioning and Leasing: an Optimization Model. PhD. Dissertation, Polytechnic Institute of New York. 
Francesco, M., Craini, T. G., \& Zuddas, P. (2009). The effect of multi-scenario policies on empty container repositioning. Transportation Research Part E, 45, 758-770. https://doi.org/10.1016/j.tre.2009.03.001

Francesco, M., Lai, M. T. G., \& Zuddas, P. (2013). Maritime repositioning of empty containers under uncertain port disruptions. Computers \& Industrial Engineering, 64, 827-837. https://doi.org/10.1016/j.cie.2012.12.014

Furio, S., Andres, C., Diaz, B. D., \& Lozano, S. (2013). Optimization of empty container movements using street-turn: Application to Valencia hinterland. Computers \& Industrial Engineering, 66, 909-917. https://doi.org/10.1016/j.cie.2013.09.003

Goh, S. H., \& Chan, Y. (2016). Operational shadow pricing in back haul container shipping. Tranportation Research Part E, 93, 3-15. https://doi.org/10.1016/j.tre.2016.03.008

Hajeeh, A. M., \& Behbehani, W. (2011). Optimizing Empty Containers Distribution among Ports. Journal of Mathematics and Statistics, 7(3), 216-221. https://doi.org/10.3844/jmssp.2011.216.221

Hjortnaes, T., Wiegmans, B., Negenborn, R. R., Zuidwijk, R. A., \& Klijnhout, R. (2017). Minimizing cost of empty container repositioning in port hinterlands, while taking repair operations into account. Journal of Transport Geography, 58, 209-219. https://doi.org/10.1016/j.jtrangeo.2016.12.015

Huang, Y. F., Hu, J. K. H., \& Yang, B. (2015). Liner services netwrok design and fleet deployment with emtpy container repositioning. Computer \& Industrial Engineering, 89, 116-124. https://doi.org/10.1016/j.cie.2015.01.021

Jarke, M. (1981). Überwachung und Steuerung von Container-Transportsystemen (Control und Logistics of Container Transport Systems). Wiesbaden, W. Germany: Springer Gabler. https://doi.org/10.1007/978-3-663-20143-4

Jula, H., Chassiakos, A., \& Ioannou, P. (2003). Empty Container Interchange Report: Methods for Modeling and Routing of Empty Containers in the Los Angeles and Long Beach Port Area, Final Report. Long Beach, CA: Center for the Commercial Deployment of Transportation Technologies, California State University.

Kolar, P., Schramm, H. J., \& Prockl, G. (2018). Intermodal transport and repositioning of empty containers in Central and Eastern Europe hinterland. Journal of Transport Geography, 69, 73-82. https://doi.org/10.1016/j.jtrangeo.2018.04.014

Konings, R., \& Thijs, R. (2001). Foldable containers: a new perspective on reducing container-repositioning costs. European Journal of Transport and Infrastructure Research, 1(4), 333-352.

Kuzmicz, A. K., \& Pesch, E. (2018). Approaches to empty container repositioning problems in the context of Eurasian intermodal transportation. Omega, 1-20. https://doi.org/10.1016/j.omega.2018.06.004 


\section{Al Macrothink}

Business and Management Horizons

ISSN 2326-0297

2019, Vol. 7, No. 1

Lai, K. K., Lam, L., \& Chan, W. K. (1995). Shipping Container Logistics and Allocation. Journal of Operations Research Society, 46, 687-697. https://doi.org/10.1057/jors.1995.98

Lam, S. W., Lee, L. H., \& Tang, L. C. (2007). An approximate dynamic programming approach for the empty container allocation problem. Transportation Research Part C: Emerging Technologies, 15(4), 265-277. https://doi.org/10.1016/j.trc.2007.04.005

Le, D. H. (2003). The logistics of empty cargo containers in the Southern California Region, Final Report. Long Beach, CA: METRANS Transportation Center.

Lee, C. Y., \& Song, D. P. (2017). Ocean container transport in global supply chains: Overview and research opportunities. Transportation Research Part B, 95, 442-474. https://doi.org/10.1016/j.trb.2016.05.001

Leeuwen, B. V. (2016). Intermodal Container Leasing. Retrieved 12 April 2017, from http://www.world-leasing-yearbook.com/feature-of-the-month-june-2016/

Levinson, M. (2006). The Box: How the Shipping Container Made the World Smaller and the World Economy Bigger. New Jersey, USA: Princeton University Press.

Li, J. A., Leung, S., Wu, Y., \& Liu, K. (2007). Allocation of empty containers between multi-ports. European Journal of Operational Research, 182, 400-412. https://doi.org/10.1016/j.ejor.2006.09.003

Li, J. A., Liu, K., Stephen, C. S., \& Lai, K. K. (2004). Empty container management in a port with long-run average criterion. Math. Comput. Modell., 40, 85-100. https://doi.org/10.1016/j.mcm.2003.12.005

Liu, D., \& Yang, H. (2015). Joint slot allocation and dynamic pricing of container sea-rail multimodal transportation. Journal of Traffic and Transportation Engineering (English Edition), 2(3), 198-208.

Lloyd's List. Retrieved 10.04.2017, from https://www.lloydslist.com/11/sector/containers/

Long, Y., Lee, L. H., \& Chew, E. P. (2012). The sample average approximation method for empty container repositioning with uncertainties. European Journal of Operational Research, 222, 65-75. https://doi.org/10.1016/j.ejor.2012.04.018

Lopez, E. (2003). How do ocean carriers organize the empty containers reposition activity in the USA? Maritime Policiy \& Management, 30(4), 339-355. https://doi.org/10.1080/0308883032000145636

Lun, Y. H. V., Lai, K. H., \& Cheng, T. C. E. (2010). Managing Empty Containers. Shipping and Logistics Management, 151-164.

Mittal, N., Boile, M., Baveja, A., \& Theofanis, S. (2013). Determining optimal inland-empty-container depot locations under stochastic demand. Research in Transportation Economics, 42, 50-60. https://doi.org/10.1016/j.retrec.2012.11.007

Moon, I., Ngoc, A. D., \& Konings, R. (2013). Foldable and standard containers in empty 
container repositioning. Transportation Research Part E, 49, 107-124. https://doi.org/10.1016/j.tre.2012.07.005

Myung, Y. S., \& Moon, I. (2014). A network flow model for the optimal allocation of both foldable and standard containers. Operations Research Letters, 42, 484-488. https://doi.org/10.1016/j.orl.2014.08.004

Potts, R. B. (1970). Movement of Empty Containers within Australia. Paper presented at Operations Society of Virginia, Melbourne, Australia.

Shen, W. S., \& Khoong, C. M. (1995). A DSS for empty container distribution planning. Decision Support Systems, 15(1), 75-82. https://doi.org/10.1016/0167-9236(94)00037-S

Shintani, K., Imai, A., Nishimura, E., \& Papadimitriou, S. (2007). The container shipping network design problem with empty container repositioning. Transportation Research Part E: Logistics and Transportation Review, 43(1), 39-59. https://doi.org/10.1016/j.tre.2005.05.003

Shintani, K., Konings, R., \& Imai, A. (2010). The impact of foldable containers on container fleet management costs in hinterland transport. Transportation Research Part E, 46, 750-763. https://doi.org/10.1016/j.tre.2009.12.008

Slack, B., \& Gouvernal, E. (2011). Container freight rates and the role of surcharges. Journal of Transport Geography, 19, 1482-1489. https://doi.org/10.1016/j.jtrangeo.2011.09.003

Song, D. P. (2006). Characterizing optimal empty container reposition policy in periodic-review shuttle service systems. Journal of the Operational Research Society, 58(1), 122-133. https://doi.org/10.1057/palgrave.jors.2602150

Song, D. P. (2007). Analysis of a collaborative strategy in container fleet management. 11th World Conference on Transport Research, University of California, Berkeley, 24-28 June.

Song, D. P., \& Carter, J. (2009). Empty container repositioning in liner shipping. Maritime Policy \& Management, 36(4), 291-307. https://doi.org/10.1080/03088830903056934

Statista.

Retrieved

from https://www.statista.com/statistics/253988/estimated-containerized-cargo-flows-on-major-con tainer-trade-routes/

Theofanis, S., \& Boile, M. (2009). Empty marine container logistics: facts, issues and management strategies. GeoJournal, 74, 51-65. https://doi.org/10.1007/s10708-008-9214-0

UNCTAD. (2016a). Review of Maritime Transport 2016, United Nations Publication, Sales no. E.16.II.D.7, New York and Geneva. Retrieved from http://unctad.org/en/PublicationsLibrary/rmt2016_en.pdf

UNCTAD. (2016b). Harnessing emerging technological breakthroughs for the 2030 Agenda for Sustainable Development, Policy Brief No. 45. Retrieved from http://unctad.org/en/PublicationsLibrary/presspb2016d1_en.pdf

Wang, B., \& Tang G. (2010). Stochastic Optimization Model for Container Shipping of Sea 


\section{Macrothink}

Business and Management Horizons

ISSN 2326-0297

2019, Vol. 7, No. 1

Carriage. Journal of Transportation Systems Engineering and Information Technology, 10(3), 58-63. https://doi.org/10.1016/S1570-6672(09)60045-3

Wang, B., \& Wang, Z. (2007). Research on the Optimization of Intermodel Empty Container Reposition of Land-carriage. Journal of Transportation Systems Engineering and Information Technology, 7(3), 29-33. https://doi.org/10.1016/S1570-6672(07)60020-8

Wang, K., Wang, S., Zhen, L., \& Xiaobo, Q. (2017). Ship type decision considering empty container repositioning and foldable containers. Transportation Research Part E, 108, 97-121. https://doi.org/10.1016/j.tre.2017.10.003

Wang, S., Wang, H., \& Meng, Q. (2015). Itinerary provision and pricing in container liner shipping revenue management. Transportation Research Part E, 77, 135-146. https://doi.org/10.1016/j.tre.2014.06.020

White, W. W. (1972). Dynamic transshipment networks: An algorithm and its application to the distribution of empty containers. Networks, 2(3), 211-236. https://doi.org/10.1002/net.3230020304

Wong, E. Y., Allen, H. T., \& Raman, M. (2015). A maritime container repositioning yield-based optimization model with uncertain upsurge demand. Transportation Research Part E, 82, 147-161. https://doi.org/10.1016/j.tre.2015.07.007

Xie, Y., Liang, X., Lijun, M., \& Yan, H. (2017). Empty container management and coordination intermodal transport. European Journal of Operational Research, 257, 223-232. https://doi.org/10.1016/j.ejor.2016.07.053

Xu, L., Govindan, K., Bu, X., \& Yin, Y. (2015). Pricing and balancing of the sea-cargo service chain with empty equipment repositioning. Computers \& Operations Research, 54, 286-294. https://doi.org/10.1016/j.cor.2014.03.001

Yu, M., F, J. C., Lee, C. Y. (2018). Detention decisions for empty containers in the hinterland transportation system, Transportation Research Part B, 110, 188-208.

Zhang, Y., \& Facanha, C. (2014). Strategic planning of empty container repositioning in the transpacific market: a case study. International Journal of Logistics Research and Applications, 17(5), 420-439. https://doi.org/10.1080/13675567.2013.875132

Zheng, J., Sun, Z. \& Gao, Z. (2015). Empty container exchange among liner carriers, Transportation Research Part E, 83, 158-169. https://doi.org/10.1016/j.tre.2015.09.007

\section{Copyrights}

Copyright for this article is retained by the author(s), with first publication rights granted to the journal.

This is an open-access article distributed under the terms and conditions of the Creative Commons Attribution license (http://creativecommons.org/licenses/by/4.0/). 